\title{
Risk factors for ectopic pregnancy: an institutional study in a tertiary care hospital
}

\author{
Ranjita Ghadei, Swayamsiddha Mohanty*, Sushree Sovana Mishra, Debashis Giri
}

Department of Obstetrics and Gynecology, C. B. Medical College, Cuttack, Odisha, India

Received: 12 August 2019

Revised: 18 October 2019

Accepted: 04 November 2019

\section{*Correspondence:}

Dr. Swayamsiddha Mohanty,

E-mail: swayam.dr@gmail.com

Copyright: ( $)$ the author(s), publisher and licensee Medip Academy. This is an open-access article distributed under the terms of the Creative Commons Attribution Non-Commercial License, which permits unrestricted non-commercial use, distribution, and reproduction in any medium, provided the original work is properly cited.

\begin{abstract}
Background: Ectopic pregnancy is the leading cause of maternal death during the $1^{\text {st }}$ trimester of pregnancy, accounting for approximately $10 \%$ of all pregnancy related deaths. A better understanding of ectopic pregnancy risk can help prevent its occurrence. The present study was designed to evaluate the ectopic pregnancy risk factors and their strength of association with ectopic pregnancy at a tertiary care hospital.

Methods: It was a prospective study with 104 cases of ectopic pregnancy and 125 controls conducted in the Department of Obstetrics and Gynecology, SCB Medical College, Cuttack for a period of 1 year. Detailed history suggestive of risks factor for ectopic pregnancy, menstrual and obstetrics history was taken. General, systemic, abdominal and vaginal examination was done. Diagnosis of ectopic pregnancy was confirmed by clinical examination, urine pregnancy test, ultrasonography and culdocentesis and only confirmed cases were included in the study group. Healthy pregnant women were taken as control group.

Results: The study revealed that the risk of ectopic pregnancy was associated with the traditional risk factors including previous EP [Adjusted odds ratio $(\mathrm{AOR})=9.98,95 \% \mathrm{CI}: 0.89-11.1 \%$ ], previous infertility $(\mathrm{AOR}=7.29$, 95\% CI:2.53-21.0) and previous history of sterilization (AOR=12.47,95\% CI: $3.50-44.4)$ and previous history of abortion $(\mathrm{AOR}=3.10,95 \% \mathrm{CI}$ : 1.53-6.30). Age comparison between cases and controls revealed that the ODDS of having ectopic pregnancy was 4 times in the age group 30 to 35 years as compared to uterine pregnancy and this difference was statistically significant $(\mathrm{P}$ value $=0.007)$.

Conclusions: Risk factors such as previous ectopic pregnancy, induction of ovulation, intra uterine device usage, abortion as well as increased maternal age along with recent diagnostic tools aid in early detection of ectopic pregnancy in women resulting in proper and timely treatment.
\end{abstract}

Keywords: Ectopic pregnancy, Pelvic inflammatory disease, Risk factors, Tubal ligation

\section{INTRODUCTION}

Motherhood is a dream of every woman. This dream is not always pleasant but may have some nightmares through herjourney. Ectopic pregnancy is one of the nightmares and is the leading cause of maternal death during the first trimester of pregnancy, accounting for approximately $10 \%$ of all pregnancy-related deaths. ${ }^{1}$ It still remains a serious health problem for women of childbearing age. ${ }^{2}$ Morbidity due to ectopic pregnancy is in the form of infertility and ectopic recurrence. ${ }^{3}$

Ectopic pregnancy refers to the implantation of a fertilised egg in an abnormal location outside the uterine 
cavity, occurring in the fallopian tube in approximately $97.7 \%$ of cases. Other sites include the cervix, ovary, cervical region of the uterus and abdominal cavity. ${ }^{4-6}$ Various risk factors for ectopic pregnancy have been identified including pervious ectopic pregnancy, previous pelvic surgery, induction of ovulation, intra uterine device usage, history of pelvic inflammatory disease and smoking at the time of conception..$^{7-11}$

PID is the commonest cause of ectopic pregnancy. It may be due to STI mainly chlamydia and gonorrhoea and others being post abortal, puerperal or secondary to an extragenital pelvic infection or surgery. ${ }^{12}$ It has been reported by Westrom $\mathrm{L}$ that chances of ectopic after one episode of salpingitis is $12.8 \%, 30 \%$ after two episodes of salpingitis and nearly $75 \%$ after three episodes of salpingitis. $^{13}$

Intrauterine contraceptive devices (IUCD) prevents intrauterine pregnancy effectively, tubal implantation to a lesser extent and chances of ovarian pregnancy are more. CuT 380A and levenogestrol device got the lowest rate of ectopic and progestasart has got the highest rate. ${ }^{14}$ Mullerian anomalies like tubal diverticula, accessory ostia and atresia can increase the risks of ectopic pregnancy. Smoking causes ectopic by delayed ovulation, altered tubal and uterine motility and altered immunity. The risk of ectopic pregnancy increases in women who conceive via ART. Higher volume of transfer media or deep catheter insertion may predispose to tubal transfer.

The recent studies have focussed on molecular level factors. Alterations, in the molecular dialog between the blastocyst and site of implantation may lead to ectopic pregnancy. Some possible factors are lectin, integrin, matrix degrading cumulus and their inhibitors, prostaglandin, host of growth factors, cytokines and their receptors and modulator proteins. ${ }^{15,16}$

Understanding the potential risk factors of ectopic pregnancy is the key to anticipation and early diagnosis where by further complications and consequences could be avoided. Furthermore, the strategies for prevention of ectopic pregnancy can be revisited and renewed. Therefore, the current study was designed to identify the potential risks factors of ectopic pregnancy and the strength of association of the risk factors with EP in the state of Odisha, India at SCB Medical college, a tertiary care centre.

\section{METHODS}

This study was performed in the department of obstetrics and gynecology, SCB Medical College, Cuttack from January 2018 to December 2018. Diagnosis of ectopic pregnancy was confirmed by clinical examination, urine pregnancy test, ultrasonography and culdocentes is and only 104 confirmed cases were included in the study group. One hundred and twenty-five healthy pregnant women, attending prenatal clinics and labour room were included into the study as controls. Written informed consent was obtained from each participant before they were interviewed.

Detailed history such as age, parity, SES, obstetrics history, abortions and use of contraceptives were noted. Earlier surgeries, tubal ligation, tubal damage, interval of first pregnancy, and any infectious disease information such as presence of PID were also taken in detail. The diagnosis of PID was confirmed by presence of three clinical features such as fever, pain abdomen and vaginal dischage. However, no biochemical confirmatory test could be done due to limited resources, and thus presence of all 3 clinical features of PID was used as diagnostic tools of detection.

\section{Statistical analysis}

We used statistical package for social science (SPSS) version 16 for data analysis. The categorical variables were expressed in terms of number and percentages. The association between two categorical variables were assessed by chi-square test/Fischer exact test. Quantitative variables were expressed in terms of mean and standard deviation. The odds ratio was calculated by bivariate analysis. The logistic regression model was used to calculate the adjusted odds ratio. The variable which had a significance level of more than 0.2. were included in the logistic regression model. P-value less than 0.05 was considered statistically significant.

\section{RESULTS}

A total of 229 participants were included in the study with 104 females (45.4\%) with ectopic pregnancy (EP) and $125(54.6 \%)$ females with intra-uterine pregnancy (IUP) (Figure 1). The participants with ectopic pregnancy were considered as cases and that with intra-uterine pregnancy were considered as controls. The ratio between cases and controls was almost $1: 1$.

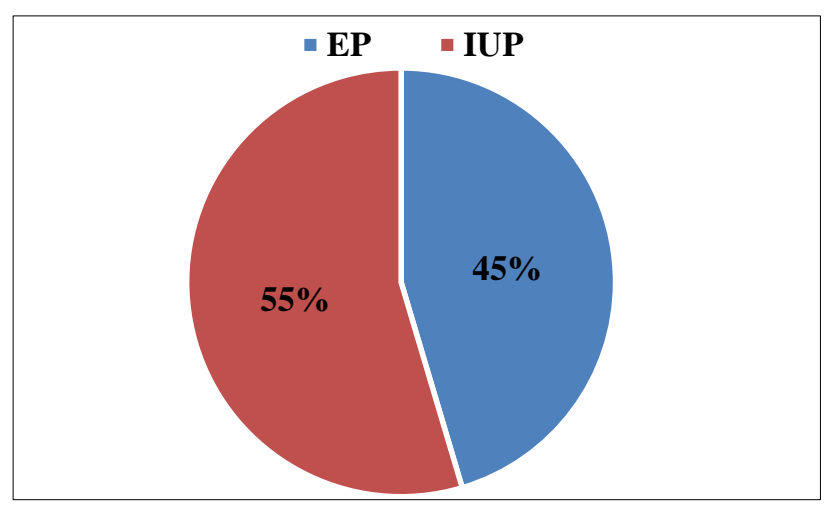

Figure 1: Proportion of cases and controls.

Table 1 shows the comparison of different obstetrics factors between the ectopic pregnancy cases with that of uterine pregnancy cases. Age comparison between cases and control revealed that the odds of having ectopic 
pregnancy was four times in age group 30 to 35 years compared to uterine pregnancy and this difference was statistically significant $(P$ value $=0.007)$. Similarly, history of abortion and previous history of ectopic pregnancy increases the odds of ectopic pregnancy by 2.5 and 9 times respectively. There were 6-times increase odds of ectopic pregnancy in patients having history of infertility which was statistically significant $(\mathrm{P}=<0.001)$. We did not find any statistically significant difference with respect to parity and history of pelvic inflammatory disease.

Table 1: Comparison of obstetrics history between the groups.

\begin{tabular}{|c|c|c|c|c|}
\hline Factors & $\mathbf{E P}, \mathbf{N}(\%)$ & IUP, $\mathbf{N}(\%)$ & OR $(95 \%$ CI) & P value \\
\hline \multicolumn{5}{|l|}{ Age group } \\
\hline$<25$ years & $21(20.2)$ & $44(35.2)$ & Reference & \multirow{4}{*}{0.007} \\
\hline $25-30$ years & $39(37.4)$ & $47(37.6)$ & $1.73(0.88-3.40)$ & \\
\hline $30-35$ years & $30(28.8)$ & $15(12.0)$ & $4.19(1.86-9.41)$ & \\
\hline$>35$ years & $14(13.5)$ & $19(15.2)$ & $1.54(0.65-3.66)$ & \\
\hline \multicolumn{5}{|l|}{ Parity } \\
\hline 0 & $25(24.0)$ & $22(17.6)$ & Reference & \multirow{3}{*}{0.484} \\
\hline 1 & $33(31.7)$ & $44(35.2)$ & $0.66(0.31-1.36)$ & \\
\hline$>1$ & $46(44.2)$ & $59(47.2)$ & $0.68(0.34-1.36)$ & \\
\hline \multicolumn{5}{|c|}{ H/o Abortion } \\
\hline Absent & $57(54.8)$ & $94(75.2)$ & Reference & \multirow{2}{*}{0.001} \\
\hline Present & $47(45.2)$ & $31(24.8)$ & $2.50(1.42-4.37)$ & \\
\hline \multicolumn{5}{|l|}{ H/o PID } \\
\hline Absent & $92(88.5)$ & $109(87.2)$ & Reference & \multirow{2}{*}{0.772} \\
\hline Present & $12(11.5)$ & $16(12.8)$ & $0.88(0.40-1.97)$ & \\
\hline \multicolumn{5}{|l|}{ H/o Ectopic } \\
\hline Absent & $97(93.3)$ & $124(99.2)$ & Reference & \multirow{2}{*}{0.042} \\
\hline Present & $7(6.7)$ & $1(0.8)$ & $8.94(1.08-73.9)$ & \\
\hline \multicolumn{5}{|c|}{ H/o Infertility } \\
\hline Absent & $79(76.0)$ & $119(95.2)$ & Reference & \multirow{2}{*}{$<0.001$} \\
\hline Present & $25(24.0)$ & $6(4.8)$ & $6.27(2.46-15.9)$ & \\
\hline
\end{tabular}

Table 2: Comparison of surgical history and contraceptive uses between the group.

\begin{tabular}{|c|c|c|c|c|}
\hline Factors & EP, N (\%) & IUP, N (\%) & OR $(95 \% \mathrm{CI})$ & P value \\
\hline \multicolumn{5}{|c|}{ Sterilization } \\
\hline Absent & $81(77.9)$ & $119(95.2)$ & Reference & \multirow{2}{*}{$<0.001$} \\
\hline Present & $23(22.1)$ & $6(4.8)$ & $5.63(2.19-14.4)$ & \\
\hline \multicolumn{5}{|c|}{ H/o Surgery } \\
\hline Absent & $85(81.7)$ & $62(49.6)$ & Reference & \multirow{3}{*}{$<0.001$} \\
\hline $\mathrm{CS}$ & $17(16.3)$ & $57(45.6)$ & $0.21(0.11-0.41)$ & \\
\hline Other & $2(1.9)$ & $6(4.8)$ & $0.24(0.04-1.24)$ & \\
\hline \multicolumn{5}{|c|}{ Previous contraception } \\
\hline Absent & $97(93.3)$ & $122(97.6)$ & Reference & \multirow{3}{*}{0.274} \\
\hline OCP & $1(1.0)$ & $1(0.8)$ & $1.25(0.07-20.3)$ & \\
\hline IUCD & $6(5.8)$ & $2(1.6)$ & $3.7(0.74-19.1)$ & \\
\hline \multicolumn{5}{|c|}{ Current contraception } \\
\hline Absent & $93(89.4)$ & $122(97.6)$ & Reference & \multirow{3}{*}{0.017} \\
\hline OCP & $10(9.6)$ & $2(1.6)$ & $6.55(1.40-30.6)$ & \\
\hline IUCD & $1(1.0)$ & $1(0.8)$ & $1.31(0.08-21.2)$ & \\
\hline
\end{tabular}

Table 2 shows the comparison of surgical and contraceptive history between the cases and controls. History of sterilization increased the odds of ectopic pregnancy by almost 6 times which was statistically highly significant. History of CS decreased the risk of ectopic pregnancy which was also statistically significant. 
Current oral contraceptive use had shown to have statistically significant association with Ectopic pregnancy $(\mathrm{P}$ value $=0.017)$. Among previous history of contraceptive use, IUCD use was associated with 3.7 times odds of ectopic pregnancy.

Table 3 shows the Multivariate logistic regression analysis for those factors which showed a $\mathrm{p}$ value of less than 0.2. Adjusting for all other factors history of abortion ( $\mathrm{P}=<0.001)$, history of infertility $(\mathrm{P}=<0.001)$ and sterilization $(\mathrm{P}=<0.001)$ increased the odds of ectopic pregnancy significantly. History of previous surgery decreased the odds significantly. Current OCP use was higher in ectopic pregnancy group compared to control group which was statistically significant $(\mathrm{P}=0.005)$.

Table 3: Multivariate logistic regression analysis of factors.

\begin{tabular}{|c|c|c|c|}
\hline Variables & Adjusted odds ratio & $95 \% \mathrm{CI}$ & P value \\
\hline \multicolumn{4}{|l|}{ Age group } \\
\hline$<25$ years & Reference & 1 & \\
\hline 25-30 years & 0.92 & $0.40-2.14$ & 0.861 \\
\hline 30-35 years & 1.65 & $0.58-4.63$ & 0.341 \\
\hline$>35$ years & 0.48 & $0.16-1.42$ & 0.189 \\
\hline \multicolumn{4}{|c|}{ H/o Abortion } \\
\hline Absent & Reference & 1 & \multirow{2}{*}{0.002} \\
\hline Present & 3.10 & $1.53-6.30$ & \\
\hline \multicolumn{4}{|l|}{ H/o Ectopic } \\
\hline Absent & Reference & 1 & \multirow{2}{*}{0.061} \\
\hline Present & 9.98 & $0.89-11.1$ & \\
\hline \multicolumn{4}{|c|}{ H/o Infertility } \\
\hline Absent & Reference & 1 & \multirow{2}{*}{$<0.001$} \\
\hline Present & 7.29 & $2.53-21.0$ & \\
\hline \multicolumn{4}{|l|}{ Sterilization } \\
\hline Absent & Reference & 1 & \multirow{2}{*}{$<0.001$} \\
\hline Present & 12.47 & $3.50-44.4$ & \\
\hline \multicolumn{4}{|l|}{ H/o Surgery } \\
\hline Absent & Reference & 1 & \multirow{2}{*}{$<0.001$} \\
\hline Present & 0.239 & $0.11-0.49$ & \\
\hline \multicolumn{4}{|c|}{ Current contraception } \\
\hline Absent & Reference & 1 & \\
\hline $\mathrm{OCP}$ & 12.41 & $2.1-73.1$ & 0.005 \\
\hline IUCD & 2.05 & $0.08-48.97$ & 0.655 \\
\hline
\end{tabular}

\section{DISCUSSION}

With the development of newer methods of management and treatment of ectopic pregnancy, the mortality and morbidity of this condition is slowly decreasing. The mean age with ectopic pregnancy in the present study was 27.5 years, with the predominant age group being 25-30 years. In a study by Anorlu et al, mean age of the patient was 27.8 years, which was in concordance with the present study. ${ }^{17}$ Most of the women in India get married and complete their family at an early age. This is in correspondence to the age of peak sexual activity and reproduction.

Most of the patient were multigravida with the mean gravid status being greater than one. In the study by Bhavana et al, the multigravida status was seen in more the $80 \%$ of the cases and $81.7 \%$ in a stud by Panchal et al, which was in agreement with the present study. ${ }^{18,19}$

A previous history of ectopic pregnancy was one of the risk factor for a consequent incidence which was seen in around $6.7 \%$ of cases in our study. Previous ectopic pregnancy had the eight times odds of having subsequent ectopic pregnancy' other studies also have reported a strong association between previous ectopic pregnancy and the present one, with one study reporting a 17 times higher rate in women with previous ectopic pregnancy compared to the controls. ${ }^{20}$

History of previous abortion in our study had a significant effect on ectopic pregnancy $(\mathrm{AOR}=3.10)$. This is supported by Bouyer $\mathbf{J}$ et al, study in which the adjusted risk of ectopic pregnancy being particularly high 
in women with two or more previous spontaneous abortions $\left(\mathrm{AOR}=1.2\right.$ and 3.0 respectively). ${ }^{5}$ Previous abortion (spontaneous or induced) may have a causal effect, possibly mediated by infection. However, there may also be common risk factors for ectopic pregnancy and spontaneous abortions, such as chromosomal abnormalities or hormonal factors. However, studies by Parashi et al and Coste et al have shown no significant association between the two. ${ }^{21}$

PID was observed in $11.5 \%$ of the patients with ectopic pregnancy with an odds ratio of 0.88 (95\% CI: 0.40 1.97). We did not find any statistically significant difference with respect to history of PID and ectopic pregnancy occurrence. Only clinical criteria were taken up for diagnosis of PID where most of the patients with chlamydia infection remained asymptomatic. No objective biological markers like IgG against chlamydia or gonococcus could have been done as it was a resource poor setting.

Tubal ligation was another risk factor which attributed to increased incidence of ectopic pregnancy, $(\mathrm{AOR}=12.47$, $95 \% \mathrm{CI}=3.50$ to 44.4 ). Prior tubal surgeries in the form of tubectomies or recanalization were significant risk factors for ectopic pregnancy. A massive tubal ligation program has definitely increased the risk of pelvic inflammatory disease and in turns that of ectopic pregnancy. Uneven recanalization of the tube forces the fertilized ovum to stay in the tube resulting in ectopic pregnancy. Ectopic pregnancy should be strongly considered if a patient with previous history of tubal surgery presents with acute pain abdomen with or without amenorrhea or fainting attack.

In our study $5.8 \%$ cases and $1.6 \%$ controls had h/o previous intra uterine devices use with an odds ratio of 3.7 (95\% CI: 0.74-19.1). The increased use of IUCD as a method of contraception has resulted in the increased incidence of ectopic pregnancies as IUCD is effective in preventing the intra uterine pregnancy but has no protective effect against extra uterine pregnancy. On univariate analysis, previous use of intrauterine device (IUD) was associated with 4-fold increased risk of ectopic pregnancy. Moini et al, found that usage of IUCD increased the risk of subsequent ectopic pregnancy four to fivefold. ${ }^{22}$

Parashi et al found that usage of IUCD increases the risk of ectopic pregnancy significantly whereas oral contraceptive pills prevent ectopic pregnancy. ${ }^{23}$ In our study, the cases and controls had same incidence of ectopic pregnancy with previous history of OCP users. Current contraceptive use of OCP has shown to have statistically significant association with ectopic pregnancy $(\mathrm{P}$ value $=0.017)$.

In the present study, we found that there was a significant inverse relationship between risk factors like abdominal/ pelvic surgeries and incidence of ectopic pregnancy with an odds ratio of 0.24 (95\% CI: $0.04-1.24)$. The observed decreased association between pelvic surgeries and ectopic pregnancy is in contradiction with other studies. H/o previous LSCS was found in $16.3 \%$ cases of ectopic pregnancy, with an odds ratio of 0.21 (95\% CI: 0.11 0.41). History of CS decreased the risk of ectopic pregnancy which was also statistically significant. Reports on the association of caesarean delivery with subsequent ectopic pregnancy have yielded conflicting data, and a recently published meta-analysis by O'Neill et al concluded that there is no evidence of an association. Which is also supported by Barnhart et al. ${ }^{24,25}$

\section{CONCLUSION}

The rise in the incidence of ectopic pregnancy is going in parallel with the rise in the incidence of risk factors like sexually transmitted infections, increased tubal sterilization and reversal, delayed child bearing, ART, increased awareness about ectopic pregnancy entity and improvement in diagnostics techniques. Despite many advances in the diagnostics technique, ectopic pregnancy is still a diagnostic dilemma because of its varied clinical presentation.

Increasing awareness among sexually active women, and men regarding safe sexual practices and contraception decrease abortions and reduces the risk of ectopic pregnancy. All high risks women should be screened at the earliest with serum $\beta$-hcg and TVS. The impact on future fertility can be improved by focussing on primary prevention and early diagnosis before rupture.

Funding: No funding sources

Conflict of interest: None declared

Ethical approval: The study was approved by the Institutional Ethics Committee

\section{REFERENCES}

1. Farquhar CM. Ectopic pregnancy. Lancet. 2005;366(9485):583-91.

2. Zane SB, Kieke BJ, Kendrick JS, Bruce C. Surveillance in a time of changing health care practices: estimating ectopic pregnancy incidence in the United States. Maternal Child Health J. 2002;6(4):227-36.

3. Chow WH, Daling JR, Cates WJ, Greenberg RS. Epidemiology of ectopic pregnancy. Epidemiol Rev. 1987;9:70-94.

4. Nkusu Nunyalulendho D, Einterz EM. Advanced abdominal pregnancy: case report and review of 163 cases reported since 1946. Rural Remote Health. 2008;8(4):1087.

5. Bouyer J, Coste J, Fernandez H, Pouly JL, Job-Spira N. Sites of ectopic pregnancy: a 10 year populationbased study of 1800 cases. Hum Reprod. 2002;17(12):3224-30. 
6. Saito M, Koyama T, Yaoi Y, Kumasaka T, Yazawa K. Site of ovulation and ectopic pregnancy. Acta Obstet Gynecol Scand. 1975;54(3):227-30.

7. Coste J, Job-Spira N, Fernandez H, Papiernik E, Spira A. Risk factors for ectopic pregnancy: a casecontrol study in France, with special focus on infectious factors. Am $\mathrm{J}$ Epidemiol. 1991;133(9):839-49.

8. Fernandez H, Coste J, Job-Spira N. Controlled ovarian hyperstimulation as a risk factor for ectopic pregnancy. Obstet Gynecol. 1991;78(4):656-9.

9. Job-Spira N, Collet P, Coste J, Brémond A, Laumon B. Risk factors for ectopic pregnancy. Results of a case control study in the Rhone-Alpes region. Contracept Fertil Sex. 1993;21(4):307-12.

10. Bouyer J, Coste J, Shojaei T, Pouly JL, Fernandez H, Gerbaud L, et al. Risk factors for ectopic pregnancy: a comprehensive analysis based on a large casecontrol, population-based study in France. Am J Epidemiol. 2003;157(3):185-94.

11. Marchbanks P, Annegers JF, Coulam CB, Strathy JH, Kurland LT. Risk factors for ectopic pregnancy.A population based-study. JAMA. 1988;259(12):1823-7.

12. Diquelou JY, Pia P, Tesquier L, HenrySuchet J, Gicquel JM, Boyer S. The role of Chlamydia trachomatis in the infectious etiology of extra-uterine pregnancy. J Gynecol Obstet Biol Reprod (Paris). 1988; 17:325-32.

13. Westrom L, Joesoef R, Reynolds G, Hagdu A, Thompson SE. Pelvic inflammatory disease and fertility. Sex Trans Dis. 1992;19:185.

14. Dutta DC. Textbook of Obstetrics. $7^{\text {th }}$ edition. Jaypee Medical Publishers. Chapter 15, Hemorrhage in early pregnancy; 2013:177-189.

15. Attar E. Endocrinology of ectopic pregnancy. Obstet Gynecol Clin N Am. 2004;31:779-94.

16. Bai SX, Wang YL, Qin L, Xiao ZJ, Herva R, Piao YS. Dynamic expression of matrix metalloproteinases (MMP-2, 9 and -14) and the tissue inhibitors of MMPs (TIMP-1, -2 and -3) at the implantation site during tubal pregnancy. Reprod. 2005;129:103-13.

17. Anorlu RI, Oluwole A, Abudu OO, Adebajo S. Risk factors for ectopic pregnancy in Lagos, Nigeria. Acta Obstet Gynecol Scand. 2005;84(2):184-8.
18. Bhavna, Gupta KB, Pathania K, Jindal M, Vohra R, Ahmed M. Risk factors for ectopic pregnancy: a case control study in tertiary care centre. J Dent Med Sci. 2014;13(3):23-7.

19. Pa Panchal D, Vaishnav G, Solanki K. Study of management in patient with ectopic pregnancy. Nat $\mathrm{J}$ Inte Res Med. 2011;2(3):91-4.

20. Skjeldestad FE, Hadgu A, Eriksson N. Epidemiology of repeat ectopic pregnancy: a population -based prospective cohort study. Obstet Gynecol.1998;91:129-35.

21. Bouyer J, Coste J, Shojaei T, Pouly JL, Fernandez H, Gerbaud L, et al. Risk factors for ectopic pregnancy: a comprehensive analysis based on an International Journal of Reproduction, Contraception, Obstetrics and Gynecology. Volume 5 - Issue 8 Page 2835 large case-control, population-based study in France. Am J Epidemiol. 2003;157(3):185-94.

22. Moini A, Hosseini R, Jahangiri N, Shiva M, Akhoond MR. Risk factors for ectopic pregnancy: A case-control study. J Res Med Sci. 2014;19:844-9.

23. Parashi S, Moukhah S, Ashrafi M. Main risk factors for ectopic pregnancy: a case-control study in a sample of Iranian women. Int J Fertil Steril. 2014;8:147-54.

24. O’Neill SM, Khashan AS, Kenny LC. Caesarean section and subsequent ectopic pregnancy: a systematic review and meta-analysis. BJOG. 2013;120(6):671-80.

25. Barnhart KT, Sammel MD, Gracia CR, Chittams J, Hummel AC, Shaunik A. Risk factors for ectopic pregnancy in women with symptomatic firsttrimester pregnancies. Fertil Steril. 2006;86(1):3643.

Cite this article as: Ghadei R, Mohanty S, Mishra SS, Giri D. Risk factors for ectopic pregnancy: an institutional study in a tertiary care hospital. Int J Reprod Contracept Obstet Gynecol 2019;8:4741-6. 